\title{
Surgical site infection following cholecystectomy: comparison of procedures performed with and without a laparoscope
}

\author{
M. Jawien, J. Wojkowska-Mach, A. Rozanska, M. Bulanda, P.B. Heczko \\ Jagiellonian University Medical School, Krakow, Poland \\ doi:10.3396/ijic.V4i1.004.08
}

\begin{abstract}
The data were collected and reported by 25 hospitals participating in Nosocomial Infections Active Surveillance System of the Polish Society of Hospital Infection. Data from about 5140 cholecystectomies were collected from January 2002 through December 2003. Among these cases there were 3056 cholecystectomies with laparoscope use. The total number of SSI following cholecystectomy was 125; 92 without laparoscope use and 33 with laparoscope use. The incidence rate for SSI following cholecystectomy without and with laparoscope use was: $4.41 \%$ vs $1.08 \%$ respectively. Distribution of infection sites for cholecystectomy performed without and with laparoscope included: superficial incisional $68.5 \%$ vs $60.6 \%$; deep incisional $23.9 \%$ vs $21.2 \%$; organ/space $7.6 \%$ vs $18.2 \%$. SSI risk index ranged from $0.15 \%$ for category -1 to $27.5 \%$ for risk index category. Dominant microbes identified: cholecystectomy without laparoscope use: Escherichia.coli 23.9\%, Enterococcus sp. 18.5\%; with laparoscope use: Enterococcus sp. 20.4\%, Klebsiella sp. 15.9\%. The risk of SSI following cholecystectomy performed without a laparoscope was higher than cholecystectomy performed with a laparoscope .
\end{abstract}

\section{Introduction}

The laparoscope was introduced in the late 1980s and since then has been a popular surgical technique. Cholecystectomies are the major operative procedures using a laparoscope. Other operative procedures include: appendectomy, herniorrhaphy, colon surgery, gastric surgery and gynecologic surgery. The main advantages of laparoscopy are less postoperative pain, smaller incision and shorter hospitalization. ${ }^{1}$ Although laparoscopic cholecystectomy is less invasive, requires a shorter hospitalization and is associated with faster recovery than open cholecystectomy, little is known about the impact of laparoscopy on the risk of surgical site infections (SSI).

Equipment used in laparoscopy is very costly and it is used for many years. Rigorous conformation to disinfectionandsterilization rudimentsisveryimportant. Each disinfection and sterilization procedure has a risk of acquiring micro-damages which may be a source

\section{Corresponding author}

M. Jawien, J. Wojkowska-Mach, Jagiellonian University Medical School, Krakow, Poland 
of hepatitis B or $\mathrm{C}$ or human immunodeficiency virus infections as well as infections caused by methicillinresistant $S$. aureus, vancomycin-resistant enterococcus or atypical mycobacteria. ${ }^{2-4}$ This problem particularly affects countries with budgets devoted to the health sector lower than in developed ones.

\section{Methods}

Data were collected and reported by 25 hospitals which have been participating in the Nosocomial Infections Active Surveillance System of the Polish Society of Hospital Infection. Cholecystectomy included procedures identified by the International Classification of Diseases, Ninth Revision codes 51.03, 51.04 or 51.2 to 51.24. Standard National Nosocomial Infections Surveillance (NNIS, now the National Healthcare Surveillance Network, NHSN) System definitions were used for identification of surgical site infections. ${ }^{5,6}$ Parameters considered during the analysis included patient characteristics (sex, age, American Society of Anesthesiologist preoperative risk score, ${ }^{7}$ operation timing (duration of procedures, emergency procedures), operation characteristics (surgical wound class, multiple procedures through same incision), modified risk index (category -1 when procedure was performed with a laparoscope ${ }^{8}$ ) and microbial factors of SSI. The statistic tests that were used included: influence of selected risk factor on morbidity, Standardized Surgical Site Infection ratio, influence of SSI risk factors: Chi square test, incidence of different types of SSIs: $\mathrm{G}^{2}$ test (likelihood ratio). Statistical significance was set at the 0.05 level.

\section{Results}

Between January 2002 and December 2003 hospitals collected data on 5140 inpatient cholecystectomy procedures. Among these cases there were 3056 cholecystectomies with laparoscope use and 2084 cholecystectomies without laparoscope use. Overall, 125 SSI were reported during the study period: 33 SSI following laparoscopy cholecystectomy and 92 following open cholecystectomy. In univariate analysis, the incidence rate for SSI following laparoscopic and open cholecystectomy was $1.08 \%$ vs $4.41 \%$ (RR $=$ $1.51 ; 95 \% \mathrm{Cl} 1.36-1.68 ; \mathrm{p}<0.001)$. There was a lack of data for 329 procedures (about 6\%) and 18 cases of SSI (about 15\%).

Compared to open cholecystectomies, patients undergoing the laparoscopic technique were younger, less likely to be male, have an ASA score of 3 or more, dirty or contaminated wounds, emergency procedures or multiple procedures through the same incision. Laparoscopic procedures were shorter in duration than open procedures. Age, ASA score of 3 or more, and dirty or contaminated wounds showed statistical significance at $<0.001$ (Table I).

Most SSIs following open and laparoscopic techniques were detected during the patients stay in hospital (about $80 \%)$. SSIs were rarely detected during post-discharge follow-up (about $6 \%$ ) or on readmission (about 10\%). Rates were similar for both techniques.

\section{Table I. Characteristics of SSI following open and laparoscopic cholecystectomy}

\begin{tabular}{lrrr} 
Characteristic & $\begin{array}{r}\text { Open } \\
\mathbf{N = 9 2}\end{array}$ & $\begin{array}{r}\text { Laparoscopic } \\
\mathbf{N = 3 3}\end{array}$ & value \\
\hline Gender [\% male] & 38 & 36 & $<0,001$ \\
Age, years [mean] & 65 & 72 & $\mathrm{NS}$ \\
Age $\geq 60[\%]$ & 73 & 88 & $\mathrm{NS}$ \\
Operation duration, min [mean] & 96 & 103 & $<0,001$ \\
Contaminated/dirty [\%] & 13 & 48 & 0,03 \\
ASA score $\geq 3$ [\%] & 36 & 57 & $\mathrm{NS}$ \\
Emergency procedures, [\%] & 13 & 9 & $\mathrm{NS}$
\end{tabular}


The percentage of organ/space infections following laparoscopic procedures was higher then following open cholecystectomy ( $18 \%$ vs. $8 \%, p=0.02)$. For both the laparoscopic and open cholecystectiomies, SSIs were more likely to occur at superficial sites (about $65 \%$ ). The percentage of deep incisional infections following both techniques was similar.

The incidence rate for SSI following laparoscopic cholecystectomy was higher in patients who had one or more risk factors: age 60 years or more, an ASA score of 3 or more, contaminated or dirty wound, following emergency procedures, when multiple procedures were performed through the same incision and when operation duration was longer than 85 minutes (above $75 \%$ percentile). Significance level was below 0.001 in all analyses. Compared to laparoscopic technique, incidence rate for SSI following open cholecystectomy was higher in patients: age 60 years or more, when operation was longer than 85 minutes, with contaminated or dirty wound and when multiple procedures were performed through the same incision.

The modified NNIS risk index includes four factors: surgical wound class, ASA score, operation duration and operative technique. The duration cut point for cholecystectomies was 85 minutes. SSI morbidity was from $0.15 \%$ with risk index category -1 (when patient had no risk factors and a laparoscope was used) to $27.5 \%$ with risk index category 3 (when patient had three risk factors and an open procedure performed) (Table 2).
$70.4 \%$ of the SSIs were microbiologically confirmed (88 samples were positive). 52 (59\%) cases were polimicrobial infections. The dominant microbes identified: cholecystectomy without laparoscope use: Escherichia coli - $23.9 \%$ and Enterococcus sp. - 18.5\%; with laparoscope use: Enterococcus sp. - 20.4\%, Klebsiella sp. $-15.9 \%$ and Escherichia coli $11.4 \%$. The majority of SSI were due to Gram negative bacteria (Figure 1).

\section{Discussion}

In recent years laparoscopy has become a referential technique in cholecystectomy; in most hospitals it is performed more often than the classic surgery. ${ }^{9}$ Laparoscopy-attributable mortality reaches $0.5 \%$, morbidity $4 \%$ and surgical site infections rates following this procedure range between 0.1 to $2 \% .^{10,11}$ According to this study, the risk of acquiring SSI after cholecystectomy is lower when using a laparoscope compared to classical operation procedure. Those results are comparable to data derived from other analyses conducted in different countries. ${ }^{1,11,12}$ In every study the most important risk factors for lower postoperative complications in cholecystectomy performed with a laparoscope are: experience of operation team and proper choice of patient for the procedure, including all possible contraindications. ${ }^{1}$

TheSSI risk index is specific for every surgical procedure. It was proposed by Haley, who chose selected factors, such as: surgical wound class, ASA value and time of operation. He identified these as the most important risk factors determining occurrence of SSI. In certain

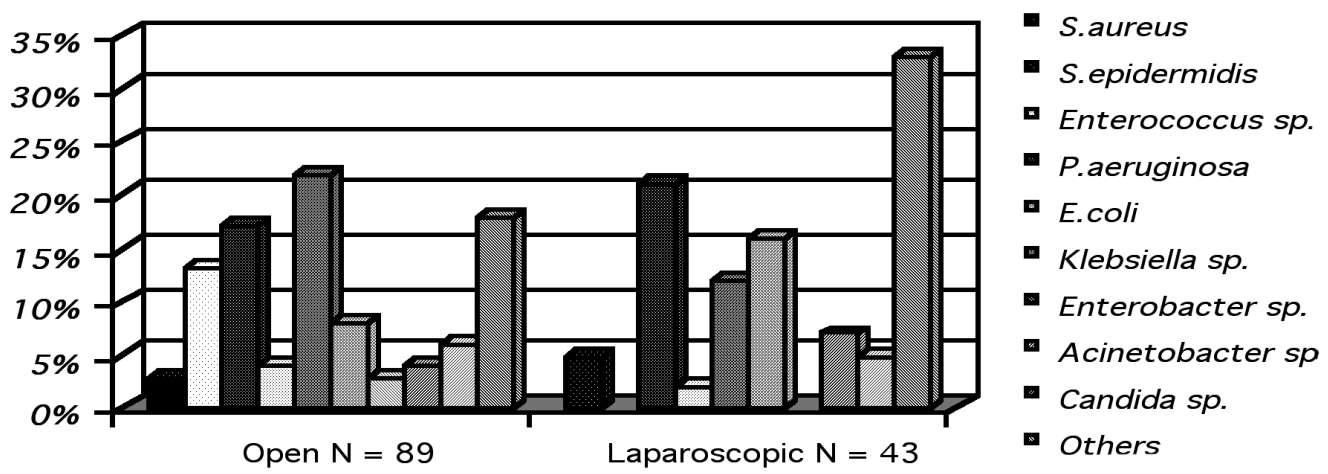

Figure 1. Dominant pathogens associated with SSI following cholecystectomy ( $\mathrm{N}=$ number of strains) 
Table II. SSI rate according to the Modified National Nosocomial Infections Surveillance System Risk Index

\begin{tabular}{lrrrrrr} 
Index & $\begin{array}{r}\text { No of operations } \\
\text { N=5140 }\end{array}$ & $\begin{array}{r}\text { No of SSI } \\
\mathbf{N = 1 2 5}\end{array}$ & $\begin{array}{r}\text { Incidence rate } \\
\text { PTZS }^{*}\end{array}$ & $\begin{array}{r}\text { Incidence rate } \\
\text { NNIS ** }\end{array}$ & $\begin{array}{r}\text { Expected No } \\
\text { of SSI }\end{array}$ & SIR SSI *** \\
\hline-1 & 1950 & 3 & 0,15 & 0,45 & 8,7 & 0,34 \\
0 & 1767 & 31 & 1,75 & 0,68 & 12,0 & 2,58 \\
1 & 827 & 49 & 5,93 & 1,78 & 14,7 & 3,33 \\
2 & 238 & 16 & 6,72 & 3,27 & 7,8 & 2,05 \\
3 & 29 & 8 & 27,5 & 5,68 & 1,6 & 4,87 \\
\hline Lack of data & 329 & 18 & & & & \\
Total & $\mathbf{5 1 4 0}$ & $\mathbf{1 2 5}$ & & & & \\
\hline
\end{tabular}

$P$ value $=0,34$

Number do not always add up total, because of missing values; duration cut point was 85 min;

* Polish Society of Hospital Infection

** National Nosocomial Infections Surveillance

*** Standardized Infection Ratio = observed number of SSI / expected number of SSI

operative procedures a modified risk index may be used. This index focuses on specialty procedures comprising homogeneous patient populations. Patient population is divided into two groups for analysis: those of higher and lower risk. ${ }^{13-15}$

In digestive tract surgery, especially in such procedures as cholecystectomy, appendectomy, colon surgery and stomach surgery, technique, there is an additional risk factor. Technique can be separated into use of a laparoscope or classic surgery. In assessing risk index among patients undergoing cholecystectomy or colon surgery total value is lowered by one point. So, the new value: "-1" appears in the SSI risk index, characterizing patient without basic risk factors, after cholecystectomy performed with laparoscope. ${ }^{1,8}$

Using the modified risk index is proper only if the percentage of missing data is small. The differences between Polish results and those obtained in NNIS are the proof of this. ${ }^{1,15}$

Because of short patient stay in hospital after laparoscopic surgery there is a possibility that an SSI will appear after discharge. Consequently, it will be missed in data gathered by the infection control team. Thus, well organized surveillance after discharge in surgical outpatient clinics is important. This is one of the most difficult infection control activities, in Poland and in other countries. ${ }^{16,17}$ It is assumed that without post-discharge surveillance one third of all cases of SSI will be missed. ${ }^{18}$

Most individuals who work in the field of video surgery place an emphasis on the step of qualifying patients for surgery. Each additional risk factor, emergency/ multiprocedure surgery as well as advanced inflammatory state of the operated organ, significantly increase the risk of infection as compared to classic procedures. . $^{219,20}$

An example of improper qualification of patients was noted in a group of patients with 3 risk factors who underwent laparoscopic cholecystectomy. There was an increase in the level of exposure to SSI according to the principles of modified risk index; however a decrease in the population in this group and a rise in the incidence rate led to significantly different analyses from those reported in other infection control programs. ${ }^{2,21,22}$

Notably, some of the above mentioned patients should not have been operated on laparoscopically. The discrepancies may result from lack of experience in reliable collection of patient and procedure data. This may also point to insufficient cooperation between the infection control team and the personnel in the ward and in the operating theatre. 
A statement may be formulated based on all of the above: Analysis using the recommended method, i.e., the risk index, describing SSI incidence should be very carefully interpreted in patients of Polish hospitals despite the data being similar to results described in the literature. ${ }^{23-25}$ To conclude, the lower risk of developing an SSI after laparoscopy is the result of good cooperation between surgeons, the infection control team and staff of the surgical outpatient clinic.

\section{Conclusions}

The overall risk of SSI was significantly higher for open cholecystectomy than for laparoscopic cholecystectomy. Laparoscopy is associated with a lower risk of SSI, but only when patients are candidates for the technique.

\section{References}

1. Richards C, Edwards J, Culver DH, Emori TG, Tolson J, Gaynes R. Does using a laparoscopic approach to cholecystectomy decrease the risk of surgical site infection? Ann Surg 2003; 237 (3): 358-362.

2. Lieb O. Risk of infection transmission in endoscopy: the role endoscope processing and microbiological controls. Hyg Med 2002; 7/8: 285-296.

3. Sethi S, Sharma M, Ray P, Singh M, Gupta A. Mycobacterium fortuitum wound infection following laparoscopy. Indian I Med Res 2001; 113: 83-84.

4. Jagdish N, Sameer R, Omprakash R. Port-site tuberculosis: a rare complication following laparoscopic cholecystectomy. Scand I Infect Dis 2002; 34(12): 928-929.

5. Emori TG, Culver DH, Horan TC, et al. National Nosocomial Infections Surveillance System (NNIS): description of surveillance methodology. Am / Infect Contr 1991; 19: 1935.

6. Horan TC, Gaynes RP, Martone WJ, et al. CDC definitions of nosocomial surgical site infections, 1992: a modification of CDC definitions of surgical wound infections. Infect Contr Hosp Epidemiol 1992; 13: 606-608.

7. Keats AS. The ASA classification of physical status - a recapitulation. Anesthesiology 1978; 49: 233-236.

8. Richards C, Edwards JE, Gaynes RP. Risk factors for surgical site infection following cholecystectomy: the importance of the laparoscope. Infect Contr Hosp Epidemiol 2000; 21: 62.

9. Owings MF, Kozak LJ. Ambulatory and inpatient procedures in the United States, 1996.National Center for Health Statistics. Vital Health Stat 13 1998; 139: 1-119.

10. Jarrell BE, Carabasi RA. Surgery. $3^{\text {rd }}$ edition. Williams \& Wilkins, 1996.
11. Steiner CA, Bass EB, Talamini MA, et al. Surgical rates and operative mortality for open and laparoscopic cholecystectomy in Maryland. N Engl J Med 1994; 330: 403-408.

12. McGuckin M, Shea JA, Schwartz JS. Infection and antimicrobial use in laparoscopic cholecystectomy. Infect Contr Hosp Epidemiol 1999; 20 (9): 624-626.

13. Haley RW, Culver DH, White JW, et al. Identifying patients at high risk of surgical wound infections; a simple multivariate index of patient susceptibility and wound contamination. Am J Epidemiol 1985; 121: 206-215.

14. Culver DH, Horan TC, Gaynes RP, et al. Surgical wound infection rates by wound class, operative procedure and patient risk index. Am J Med 1991; 91(suppl 3B): S152-157.

15. Gaynes RP, Culver DH, Horan TC, et al. The National Nosocomial Infections Surveillance System. Surgical site infections (SSI) rates in the United States, 1992-1998. The National Nosocomial Infections Surveillance System Basic SSI Risk Index. Clin Infect Dis 2001; 33 (suppl 3):S69-77.

16. Sands K, Vineyard G, Livingston J, et al. Efficient identification of postdischarge surgical site infections: use of automated pharmacy dispensing information, administrative data and medical record information. I Infect Dis 1999; 179: 434441.

17. Sands K, Vineyard G, Platt R. Surgical site infections occurring after hospital discharge. J Infect Dis 1996; 173: 963-970.

18. Stockley MJ, Allen RM, Thomlinson DF, Constantine CE. A district general hospital's method of post-operative infection surveillance including post-discharge follow-up, developed over a five-year period. J Hosp Infect 2001; 49: 58-54.

19. Chuang SC, Lee KT, Chang WT, Wang SN. Risk factors for wound infection after cholecystectomy. I Formos Med Assoc 2004; 103: 607-12.

20. den Hoed PT, Boelhouwer RU, Veen HF, Hop WCJ, Bruining HA. Infections and bacteriological data after laparoscopic and open gallbladder surgery. J Hosp Infect 1998; 39: 27-37.

21. National Nosocomial Infections Surveillance (NNIS) System Report, data summary from January 1992 through June 2004, issued October 2004. Am J Infect Contr 2004; 32: 470-85.

22. Nationales Referenzzentrum fur Surveillance von Nosocomialen Infectionen: Referenzdaten Modul OP-KISS. Berlin 2003.

23. Jodra M, Rodela R, Martinez M. Standardized infection ratio for three general surgery procedures: a comparison between Spanish hospitals and US Centers participating in the National Nosocomial Infections Surveillance System. Infect Contr Hosp Epidemiol 2003; 24: 744-748.

24. Brandt C, Hansen S, Sohr D, Daschner F, Ruden H, Gastmeier P. Finding as method for optimizing risk adjustment when comparing surgical-site infection rates. Infect Contr Hosp Epidemiol 2004; 25: 313-18.

25. Narong MN, Thongpiyapoom S, Thaikul N, Jamulitrat S, Kasatpibal N. Surgical site infections in patient undergoing major operations in a university hospital: using standardized infection ratio as a benchmarking tool. Am J Infect Contr 2003; 31: 274-79. 